\title{
Preparation, Study and Nanoscale Growth of Indium Oxide Thin Films
}

\author{
A. Bagheri Khatibani ${ }^{a * *}$, S.M. Rozati ${ }^{b}$ And Z. BARGBidi ${ }^{b}$ \\ ${ }^{a}$ Islamic Azad University, Lahijan Branch, P.O. Box 1616, Lahijan, Iran \\ ${ }^{b}$ Physics Department, University of Guilan, Rasht 41335, Iran
}

(Received April 20, 2011; revised version January 15, 2012; in final form February 21, 2012)

\begin{abstract}
Indium oxide $\left(\mathrm{In}_{2} \mathrm{O}_{3}\right)$ thin films were deposited on glass substrate by varying substrate temperature in the range of $400-600^{\circ} \mathrm{C}$ using the spray pyrolysis technique. In this research, physical properties of indium oxide thin films were studied and then nanocrystalline sizes at different substrate temperature were deeply compared and investigated. All films were characterized at room temperature using X-ray diffraction, scanning electron microscopy, atomic force microscopy, photoluminescence, the Hall effect and UV-visible spectrophotometer. The optimal substrate temperature to obtain films of high crystallographic quality was $575^{\circ} \mathrm{C}$, for this temperature, the electrical resistivity was in the order of $\rho=0.147 \Omega \mathrm{cm}$. For comparing optical transmittance and electrical conductivity the best figure of merit of the films was achieved at $575{ }^{\circ} \mathrm{C}$.
\end{abstract}

PACS: 81.07.-b, 78.66. $-\mathrm{w}$

\section{Introduction}

Indium oxide $\left(\operatorname{In}_{2} \mathrm{O}_{3}\right)$ thin film is a technologically important transparent conducting oxide (TCO) material. It is used in different fields like: photovoltaic devices [1], transparent windows in liquid crystal displays [2], gas sensors [3], antireflection coatings [4], electrochromic devices [5], and solar cells [6].

Thin films of $\mathrm{In}_{2} \mathrm{O}_{3}$ can be prepared by a variety of techniques such as chemical vapour deposition [7], spray pyrolysis [8], vacuum evaporation [9], and magnetron sputtering [10]. Among these techniques, the chemical spray pyrolysis technique is one of the most commonly used techniques for preparation of transparent and conducting oxides owning to its simplicity, non-vacuum system of deposition, and hence inexpensive method. It can be easily modified for mass production and device quality oxide films can be obtained over a large area. $\operatorname{In}_{2} \mathrm{O}_{3}$ transparent conducting thin films are $n$-type semiconductors with wide energy band gap equal to $3.6 \mathrm{eV}$. The structure of $\operatorname{In}_{2} \mathrm{O}_{3}$ in its crystalline form is body centered cubic with lattice constant $a=10.118 \AA$ [11].

\section{Experiments}

In this work, $\operatorname{In}_{2} \mathrm{O}_{3}$ thin films were prepared on soda lime glass substrates using spray pyrolysis technique. The spray pyrolysis apparatus used in this work consists of a homemade spraying unit, a substrate holder with heater, and an enclosure. The glass substrate is kept on a stainless steel (ss) plate. The heater is capable of heating the substrate up to a temperature of $700{ }^{\circ} \mathrm{C}$. For preparation of $\mathrm{In}_{2} \mathrm{O}_{3}$ thin films, $\mathrm{InCl}_{3}(0.2 \mathrm{~g})$ was dissolved with 5 droplets of $\mathrm{HCl}$ acid and heated at $90^{\circ} \mathrm{C}$

* corresponding author; e-mail: bagherikhatibani@gmail.com for 5 min by reflux. The solution was sprayed perpendicularly onto glass substrate heated at different substrate temperatures. The carrier gas used in all the experiments was air, which was supplied by an air compressor. The air produced by the compressor was first filtered and then connected to the glass spray-gun (atomizer) through a flow meter to control its flow.

Parameters of deposition include: distance between the spray nozzle and substrates is $25 \mathrm{~cm}$, the carrier gas uses filtered compressed air, the spray rate is $191 /$ min, volume of solution is $40 \mathrm{ml}$. All the above mentioned parameters were kept constant and only substrate temperature (400$600^{\circ} \mathrm{C}$ ) was changed.

The structural aspects were investigated by X-ray diffraction (PW1840) using $\mathrm{Cu} K_{\alpha}$ radiation. The surface morphology was observed using a scanning electron microscope (SEM) Philips-X130 and HITACHI S4160. Surface measurement was done with an atomic force microscopy (AFM) by NT-MDT equipment - SPM Solvers, PNL NTEGRA. Electrical resistivity and carrier concentration and the Hall mobility were calculated from the Hall effect measurement by the Van der Pauw method using PhysTech system. Optical transmission for samples was measured with a UV-visible spectrophotometer Cary 100. Therefore optical transmission to near infrared region was performed with a HITACHI NO.228-1050 UV-VIS-NIR spectrophotometer, the analysis being extended to $\lambda=2600 \mathrm{~nm}$. The photoluminescence (PL) measurements were performed at room temperature. The excitation source was $320 \mathrm{~nm}$ line of $\mathrm{He}-\mathrm{Cd}$ laser, and a $320 \mathrm{~nm}$ filter was used.

\section{Results and discussion}

Figure 1 shows the XRD patterns as a function of substrate temperature for the $\operatorname{In}_{2} \mathrm{O}_{3}$ thin films. Results show that the films deposited at substrate temperature of $400{ }^{\circ} \mathrm{C}$ are amorphous in structure, while these films 

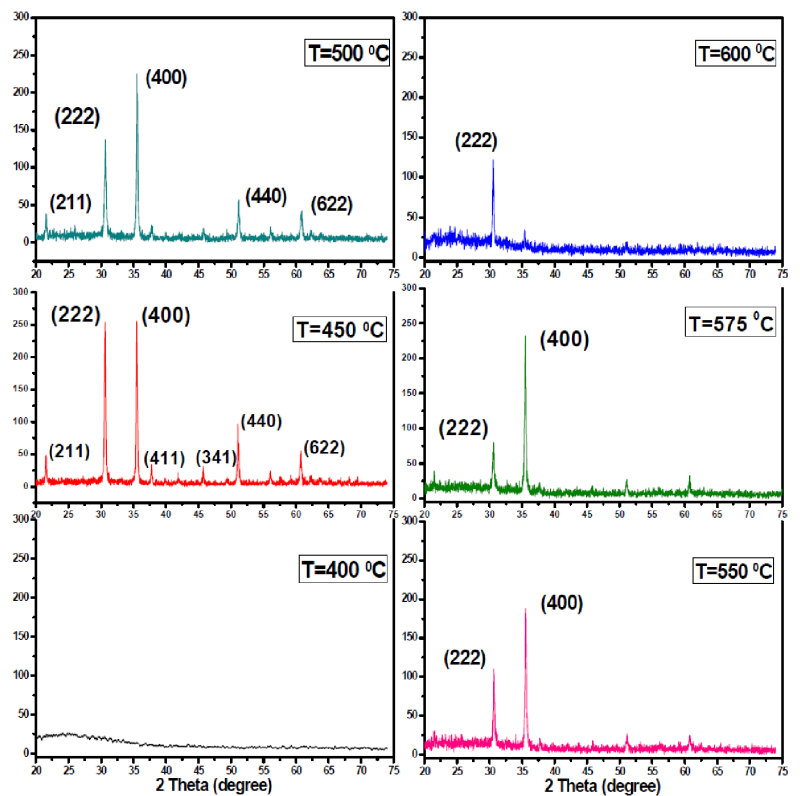

Fig. 1. XRD patterns of $\operatorname{In}_{2} \mathrm{O}_{3}$ films prepared at various substrate temperature. can be polycrystalline with increase in the substrate temperature and as a result the preferential orientations of (400), (222) prevail. All peaks observed in XRD pattern confirm the cubic bixbyte structure [12]. According to Fig. 1, the XRD intensity of preferred growth orientation is highly dependent on the substrate temperature. The intensity ratio of the peaks (400) and (222) are similar at $T_{\mathrm{s}}=450{ }^{\circ} \mathrm{C}$. The extent of $(400)$ orientation increases with substrate temperature up to $T_{\mathrm{s}}=575^{\circ} \mathrm{C}$, after which there is a decrease in extent of (400) orientation and an increase in (222) orientation when substrate temperature is at $600{ }^{\circ} \mathrm{C}$.

The mean crystallite size $D$ was calculated for the diffraction peaks using Scherrer's formula [13]:

$$
D=\frac{k \lambda}{\beta \cos \theta},
$$

where $k$ is constant value, $\theta$ is scattering angle value and $\beta$ is full width at half maximum (FWHM). With increasing substrate temperature from $575^{\circ} \mathrm{C}$ to $600{ }^{\circ} \mathrm{C}$, the grain size decreases from $36.02 \mathrm{~nm}$ to $33.55 \mathrm{~nm}$, decrease of the grain size is accompanied with sheet resistance increment and leads to mobility decrease (Table) [14] .

TABLE

The variation of electrical properties of $\operatorname{In}_{2} \mathrm{O}_{3}$ films as a function of substrate temperature.

\begin{tabular}{c|c|c|c|c|c|c}
\hline \hline$T_{\mathrm{s}}\left[{ }^{\circ} \mathrm{C}\right]$ & $R_{\mathrm{sh}}[\mathrm{k} \Omega / \square]$ & $\rho[\Omega]$ & $n\left[\times 10^{18} \mathrm{~cm}^{-3}\right]$ & $\mu\left[\mathrm{cm}^{2} /(\mathrm{V} \mathrm{s})\right]$ & $T_{\max }[\%]$ & $\mathrm{FOM}\left[\times 10^{-7} \Omega^{-1} \mathrm{~cm}\right]$ \\
\hline 400 & 16.6 & 1.060 & 0.99 & 5.94 & 13 & $8.3 \times 10^{-7}$ \\
450 & 124 & 6.5 & 0.07 & 13.50 & 51 & 0.096 \\
500 & 13 & 0.416 & 4.65 & 3.23 & 68.5 & 17.5 \\
550 & 10 & 0.121 & 13.90 & 3.71 & 79.6 & 102 \\
575 & 5.85 & 0.147 & 6.30 & 6.71 & 77 & 125 \\
600 & 20 & 0.340 & 9.55 & 1.92 & 77.4 & 38.6
\end{tabular}

Figure 2 shows SEM images of $\mathrm{In}_{2} \mathrm{O}_{3}$ thin films prepared at different substrate temperatures. According to the SEM photographs, films deposited at $400{ }^{\circ} \mathrm{C}$ have a porous and non-uniform surface.

Results show that increase in substrate temperature highly affects the surface morphology of the films, especially grains dimension throughout the film. Deposited films at lower temperatures have not suitable surface morphology, while increasing the substrate temperature causes the improvement in structure and as a result the uniformity of the films is enhanced. According to the XRD spectra, by increasing in substrate temperature from $400{ }^{\circ} \mathrm{C}$ to $550{ }^{\circ} \mathrm{C}$ all films are exhibiting the polycrystalline structure with (400) and (222) to be the dominant orientations. By increasing the substrate temperature, the grains start to grow and the surface covered fully with fine and large grains. Increase in grains size led to the decrease in the density of grain boundary, therefore the carrier concentration and the conductivity enhances (Table) [14]. By further increase in substrate temperature $\left(550{ }^{\circ} \mathrm{C}\right.$ to $\left.600^{\circ} \mathrm{C}\right)$ the XRD spectrum shows improved crystalline structure (specific sharp peaks) and as a result better optical properties (higher transmittance) (Fig. 1 and Fig. 5) [15].

Typical AFM images of $\mathrm{In}_{2} \mathrm{O}_{3}$ films deposited at different substrate temperature are shown in Fig. 3. As shown in figure, the substrate temperature affects greatly the surface morphology of the deposited films. Films deposited at lower temperature have not suitable surface quality, while further increase in substrate temperature $\left(575^{\circ} \mathrm{C}\right.$ to $\left.600^{\circ} \mathrm{C}\right)$ the better surface quality and crystallographic structure are obtained. This is in close agreement with XRD and SEM observation.

To investigate the optical properties of $\mathrm{In}_{2} \mathrm{O}_{3}$ thin films photoluminescence measurements are performed. Figure 4 shows the PL emission spectra of films deposited 


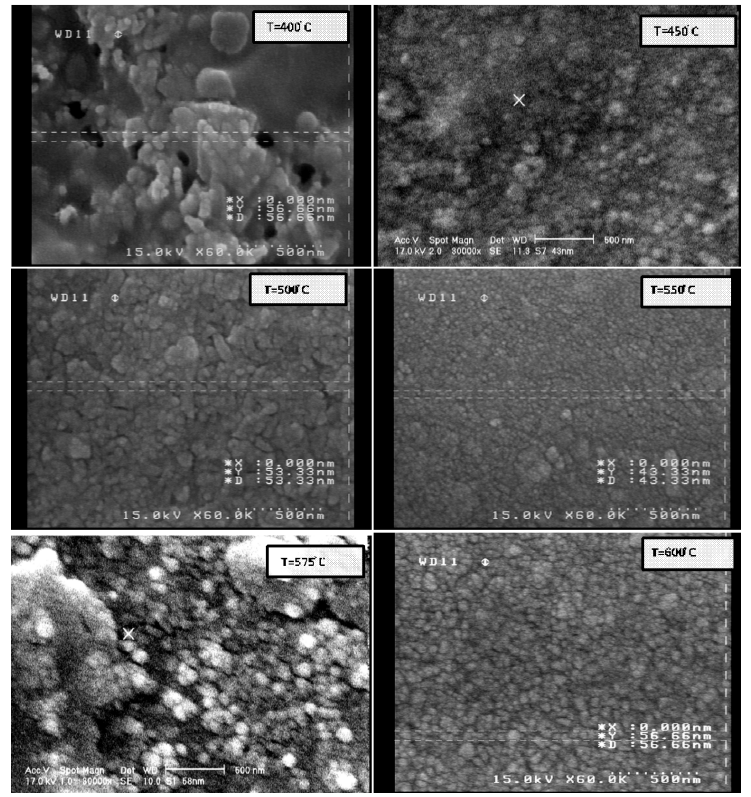

Fig. 2. SEM images of $\operatorname{In}_{2} \mathrm{O}_{3}$ films prepared at different substrate temperature.

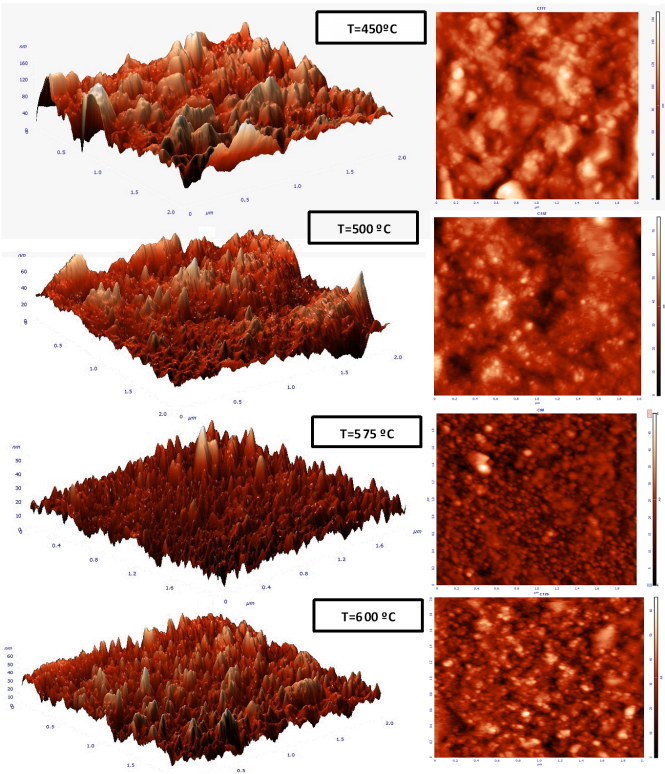

Fig. 3. AFM images of $\operatorname{In}_{2} \mathrm{O}_{3}$ films prepared at different substrate temperature.

at different substrate temperature with a beam incident of about $320 \mathrm{~nm}$. As seen, $320 \mathrm{~nm}$ incident wavelength is in UV range but acquired peaks are in the visible solar spectrum.

A strong near band edge ultraviolet emission peak can be observed for all samples. It is well understood that photoluminescence spectra depends on the structure and the stoichiometry of the prepared films [16]. Therefore the $\mathrm{PL}$ results confirm that the obtained optimum $\mathrm{In}_{2} \mathrm{O}_{3}$

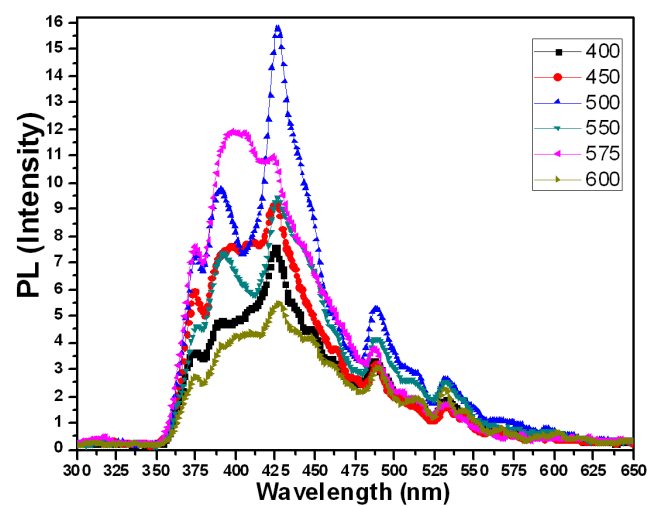

Fig. 4. PL spectra of $\operatorname{In}_{2} \mathrm{O}_{3}$ films prepared at various substrate temperatures.

thin films are very close to stoichiometry and are optically high quality. This matter is observable obviously for prepared sample at substrate temperature of $575{ }^{\circ} \mathrm{C}$. PL peak of prepared sample at $450{ }^{\circ} \mathrm{C}$ deposition temperature has also good width but its intensity is smaller than the film deposited at $575{ }^{\circ} \mathrm{C}$. The absorbed peak in $425 \mathrm{~nm}$ wavelength for prepared sample at $450^{\circ} \mathrm{C}$ deposition temperature is compatible with sharp peaks in XRD spectrum. From PL diagram one may conclude that whenever there is an increase in the deposition temperature, the crystallinity improves and as a result the indium oxide films gets better structure, but for films deposited at $600{ }^{\circ} \mathrm{C}$, the intensity of the PL peak reduced considerably which is in good agreement with the XRD results (Fig. 1).

Figure 5 shows the optical transmittance curves as a function of the wavelength for the $\mathrm{In}_{2} \mathrm{O}_{3}$ thin films deposited at various substrate temperatures. It can be observed that the optical transmittance of the films was affected by the deposition temperature. The optical transmittance observed in the films changed from $13 \%$ to $77 \%$ with the increase of deposition temperature. The high transmittance observed in the films was attributed to less scattering effects, structural homogeneity and better crystallinity. There was a shift in the absorption edge to shorter wavelength for the optimum film, which was in accordance with the Burstein-Moss shift [17].

The electrical properties were determined using room temperature Hall effect measurements in the van der Pauw configuration [18]. The negative sign of the Hall coefficient confirms the $n$-type conductivity [19].

The variation of electrical properties as a function of substrate temperature is shown in Table. From the table, one can note that the resistivity decreases from $\rho=65 \times 10^{-1} \Omega \mathrm{cm}$ (films deposited at $450^{\circ} \mathrm{C}$ ) to $\rho=1.47 \times 10^{-1} \Omega \mathrm{cm}$ (films deposited at $575^{\circ} \mathrm{C}$ ). The changes in resistivity are due to an increase in carrier density while increasing substrate temperature [20]. It could also relate to an improvement of crystallinity leading to a decrease of donor sites trapped at the dislocations and grain boundaries [21]. 


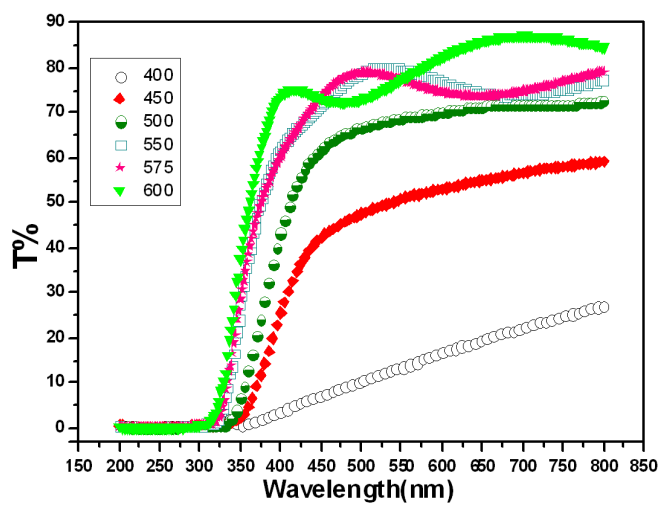

Fig. 5. Optical transmission of $\operatorname{In}_{2} \mathrm{O}_{3}$ films prepared at different substrate temperature.

The optical transmittance and electrical conductivity are two important parameters through which quality of the transparent conducting oxides are judged. These two parameters are inversely proportional to each other. A method of correlating these properties in TCO films is figure of merit that was calculated in Table [22]. Since we were looking for a layer with both high transparency and low resistivity, we used figure of merit (FOM). Thus the optimized layer at substrate temperature $T_{\mathrm{s}}=575^{\circ} \mathrm{C}$ was selected according to the most FOM.

\section{Conclusions}

Thin films of $\mathrm{In}_{2} \mathrm{O}_{3}$ were deposited by spray pyrolysis perpendicularly onto glass (soda lime) substrates using not heated (room temperature) $0.023 \mathrm{M} \mathrm{InCl}_{3}$ solution. Substrate temperature was in the range from 400 to $600^{\circ} \mathrm{C}$. Results show that the substrate temperature is one of the main process parameters and has an important effect on physical properties of the prepared films. Structural, morphological, optical and electrical properties of the films were studied and optimized conditions are achieved.

The X-ray diffraction studies revealed that the films formed at substrate temperature of $400^{\circ} \mathrm{C}$ were amorphous while those formed at temperatures $\geq 450^{\circ} \mathrm{C}$ were polycrystalline. By using Scherrer's formula for two temperatures we calculated grain size and found similarity with SEM. The SEM and AFM analysis revealed that at substrate temperature of $575{ }^{\circ} \mathrm{C}$, the prepared films exhibited more smoothness and good crystallographic structure. In PL analyses, the results confirm that the obtained optimum $\mathrm{In}_{2} \mathrm{O}_{3}$ thin films are very close to stoichiometry and are of optically high quality especially at substrate temperature of $575^{\circ} \mathrm{C}$.

The electrical resistivity of the films is variable but the best result as regards to career mobility is at $575{ }^{\circ} \mathrm{C}$ in accordance with other analysis for higher conductivity.

\section{Acknowledgments}

This project was supported by the Islamic Azad University, Lahijan Branch, Iran and performed in the Physics Department of the University of Guilan.

\section{References}

[1] M.K. Fung, Y.Ch. Sun, A. Ng, A.M.Ch. Ng, A.B. Djuristic, H.T. Chan, W.K. Chan, ACS Appl. Mater. Interfaces 3, 522 (2011).

[2] X. Yan, F.W. Mont, D.J. Poxson, M.F. Schubert, J.K. Kim, J. Cho, E.F. Schubert, Jpn. J. Appl. Phys. 48, 120203 (2009).

[3] L. Guo, X. Shen, G. Zhu, K. Chen, Sens. Actuators B: Chem., (2011) [doi:10.1016/j.snb.2011.01.042].

[4] H. Chen, Chin. Opt. Lett. 8, 201 (2010).

[5] C.M. White, D.T. Gillaspie, E. Whitney, S.-H. Lee, A.C. Dillon, Thin Solid Films 517, 3596 (2009).

[6] J.A. Anna Selvan, A.E. Delahoy, S. Guo, Y. Li, Solar Energy Mater. Solar Cells 90, 3371 (2006).

[7] G. Cheng, E. Stern, S. Guthrie, M.A. Reed, R. Klie, Y. Hao, G. Meng, L. Zhang, Appl. Phys. A 85, 233 (2006).

[8] N. Memarian, S.M. Rozati, E. Elamurugu, E. Fortunato, J. Phys. Status Solidi C 7, 2277 (2010).

[9] S. Golshahi, S.M. Rozati, R. Martins, E. Fortunato, Thin Solid Films 518, 1149 (2009).

[10] S. Boycheva, A.K. Sytchkova, M.L. Grilli, A. Piegari, Thin Solid Films 515, 8469 (2007).

[11] J. Zhou, Ph.D. Thesis, 2005.

[12] S.M. Rozati, T. Ganj, Renew. Energy 29, 1665 (2004).

[13] G. Korotcenkov, M. Nazarov, M.V. Zamoryanskaya, M. Ivanov, Thin Solid Films 515, 8065 (2007).

[14] S. Parthibab, V. Gokulakrishnan, K. Ramamurthi, E. Elangovan, R. Martins, E. Fortunato, R. Ganenan, Solar Energy Mater. Solar Cells 93, 92 (2009).

[15] A. El Hichou, A. Kachouance, J.L. Bubendorff, M. Addou, J. Ebothe, M. Troyon, A. Bougrine, Thin Solid Films 458, 263 (2004).

[16] M.S. Lee, W.C. Choi, E. Kim, C.K. Kim, S.K. Min, Thin Solid Films 279, 3 (1996).

[17] E. Burstein, Phys. Rev. 93, 632 (1952).

[18] L.J. van der Pauw, Philips Res. Rep. 13, 1 (1958).

[19] L.J. van der Pauw, Philips Tech. Rev. 20, 220 (1959).

[20] M.M. Bagheri Mohagheghi, M. Shokooh Saremi, Semicond. Sci. Technol. 18, 97 (2003).

[21] Y. Shigesato, S. Takaki, T. Haranoh, Appl. Surf. Sci. Technol. 269, 48 (1991).

[22] G. Haack, J. Appl. Phys. 47, 4086 (1976). 